\title{
ANALYSIS OF THE EFFECT OF THE SPEED FACTOR ON HIGHWAY SAFETY USING THE MACHINE LEARNING METHOD
}

\author{
Vahid NAJAFI MOGHADDAM GILANI ${ }^{1 *}$, Milad SASHURPOUR ${ }^{1}$, Sobhan HASSANJANI ${ }^{2}$, Seyed Mohsen HOSSEINIAN ${ }^{1}$
}

\begin{abstract}
Speed is one of the most important factors that can significantly change the severity of accidents. Providing a model with predictive factors leads to designing traffic plans to promote safety. This study aims to create statistical models for accidents occurred on Firuzkuh highway, Iran. Moreover, the probability of each type of accident was determined using the logit model. Various modeling methods, such as backward, forward, and entering methods, were evaluated to find the best method. Finally, since the backward method had the best performance in terms of $R 2$ and goodness of fit, the logit model of accidents was created. According to the model, the independent variables of the 12-24 hours, rainy weather, a speed of 81-95 and $96-110 \mathrm{~km} / \mathrm{h}$, the lack of attention ahead and the Pride brand of vehicle increased the severity of accidents, while the variables with negative coefficients of Tuesdays, the summer and spring seasons, sunny weather, a male driver, and daylight, reduced the severity of accidents.
\end{abstract}

Address

1 School of Civil Engineering, Iran University of Science and Technology (IUST), Tehran, Iran,

2 School of Civil Engineering, University of Guilan, Rasht, Iran

* Corresponding author: vahid_najafi@alumni.iust.ac.ir

\section{Key words}

- Safety,

- Accident,

- Speed,

- Highway,

- Logit model.

\section{INTRODUCTION}

According to the views of most economists around the world, including those in modern, underdeveloped and developed countries, the need for transportation facilities for the development of economic, social, and even cultural life is strongly emphasized (Yang et al., 2018; Eisenstadt et al., 2021). Along with rapid economic growth, transportation, especially on rural roads, plays a significant role in the integrated transportation system of a country. Developing transportation facilities in Iran has dramatically increased the damage caused by accidents (Dadashpoor et al., 2019; Babaie et al., 2021). According to World Health Organization (WHO) statistics, the fatality rate in Iran is 20.5 per 100,000 population, which is of particular concern to the country. Moreover, road traffic injuries are the third leading cause of death in Iran. These statistics show the high number of accidents on the rural and urban roads of the country. Accidents also impose high costs on governments, which in developing countries cause prob- lems in other sectors due to their low gross national income.

Modeling the severity of accidents in terms of effective parameters provides the possibility of predicting the occurrence or non-occurrence of accidents. In addition, by using this type of model, one can study the impact of each factor on the likelihood of the occurrence of these road traffic accidents. Such cognition will lead to the feasibility of developing traffic safety plans for traffic engineers (Ataeian et al., 2020; Abbasi and Li, 2021), who can also have a better understanding of the factors that have a positive or negative influence on the likelihood of the occurrence of accidents.

The present study applied a logit model to achieve a model that includes vehicle accidents due to the design speed on the Firuzkuh highway, Iran. The major differences among the studies assessing the severity of accidents lie in selecting the type of model and the number and type of parameters or independent variables that are effective in evaluating the likelihood of accidents. The innovative aspect of this research is to investigate the simultaneous effect of 
different qualitative and quantitative variables on the possibility of road accidents. The qualitative variables were the road surface conditions, weather conditions, gender, age of the driver, the at-fault driver, etc., and the quantitative variable was the operating speed.

\section{LITERATURE REVIEW}

Holdridge et al. (2005) conducted a study on possible damage in a collision with fixed roadside objects in the state of Washington, USA. They investigated the impact of fixed obstacles at a city's entrance points on the severity of accidents using nested logit models. The severity of accidents was divided into five categories: damage, minor, moderate, severe injury, and fatal. Parameters such as post boxes, fences, trees, boulder rocks, guardrails, and concrete barriers were considered effective parameters. Ultimately, the proposed model showed that the use of guardrails prevented the occurrence of fatal accidents. The model also highlighted the importance of protecting vehicles from collisions with trees and fence lines that caused severe injuries or death. Other research in which the nested logit model was used was presented by Savolainen and Mannering (2007) in which parameters such as the age of the driver, highway characteristics, alcohol consumption, wearing a helmet, and illegal speed were the effective variables. Also, Chang and Mannering (1999) analyzed the severity of injury and vehicle occupancy in truck- and non-truck-involved accidents using the nested logit model. They classified the severity of accidents into four categories: damage accidents, minor injury, severe injury, and fatal injuries. A study was performed by Khorashadi et al. (2005) in which differences in the severity of injuries of rural and urban drivers in accidents involving large trucks were examined. In their research, California accident data over four years was used, and the severity of the accidents was divided into four common classes. For modeling, multiple logit models were applied for the accident analysis. Milton et al. (2008) applied a mixed logit model with random parameters in order to model the risks involving highway speeds in the state of Washington, USA. In their study of the frequency and risks involving highway speeds, they found that by the use of the mixed logit model, the daily traffic volume in each lane played a significant role in the probability of the occurrence of an accident on highways.

In Iran, Shahi et al. (2005) studied the safety status and modeling of motorcycle accidents in Tehran to achieve a model that can predict the severity of the accidents mentioned above using the logit regression method. In this research model, independent variables were selected using the statistical results of the Wald test. Finally, factors such as the uncertainty of driver license specifications, the occurrence of accidents between 04:00 am and 06:00 am, the involvement of a minivan or bus, the occurrence of an accident on a highway or a ring road, the existence of vision obstacles, the occurrence of traffic accidents between 24:00 and 02:00 am, and the presence of defective traffic signs played an important role in increasing the risk of accidents. Ayati and Abbasi (2011a) investigated the application of zero-inflated regression models in modeling, traffic flow factors and geometric designs in the incident of urban highway accidents. They found that the speed factor played an essential role in an accident with financial losses. As the speed increased, the likelihood of accidents with high financial losses but not as many fatal accidents was raised. Torabi and Moghadam (2010) modeled the severity of accidents in urban highways by the use of logit regression models and highway speed data within
Tehran to identify the factors affecting the severity of road accidents on Tehran highways. The models presented indicated the relationship between speed risk and traffic variables, including traffic volume and traffic flow speed, geometric characteristics, human, road, and vehicle factors, and weather conditions. They concluded that variables such as a driver's age under 25 years, driving with rear gears, technical defects in the vehicle, vehicle collisions with motorcycles and bicycles, bridges, head-on collisions, T-bone accidents, and multi-vehicle accidents on urban highways were among the factors that increase the risk of accidents. Moreover, the movement speed variables between $40-60 \mathrm{~km} / \mathrm{h}$, the width of a pathway between 18-22 m, and taxi cabs were the factors that always were less risky for speed. Ayati and Abbasi (2011b) inferred that the volume of passenger and non-passenger vehicles plays an essential part in the incidence of accidents on urban highways by studying the role of traffic volume and applying Poisson and negative binomial regression models. However, the volume of heavy vehicles did not have much effect. A comparison of the two models demonstrated that the accident data were often scattered, thereby showing that the negative binomial regression model with the dispersion parameter was preferable to the Poisson model. In another study, Ayati (2012) also concluded that the speed factor had an important part in the incidence of accidents with financial losses. As the speed increased, the probability of the occurrence of an accident with financial losses increased. However, the increased speed did not have that effect on fatal accidents.

Nowadays, because of problems involving the enhanced efficiency of freeway systems, the management of speed is noteworthy. Hence, examining different types of strategies for applying maximum allowed speeds, such as the maximum allowed speed $(100,110,120$, and $130 \mathrm{~km} / \mathrm{h})$ strategies on freeways, are essential. In a study performed by Delen et al. (2006), various types of strategies for applying the maximum allowed speed on freeways were introduced. Each one was examined based on traffic and safety performance and as a result of previous studies in different countries. The VISSIM traffic simulation software results showed that of the strategies applied, the maximum allowed speed on highways strategy was safer compared to other maximum allowed speeds. It was about $20 \%$ safer and $16 \%$ weaker in performance than other strategies. They also found that by reducing the maximum speed from $130 \mathrm{~km} / \mathrm{h}$ to $100 \mathrm{~km} / \mathrm{h}$, the network performance decreased by about $19 \%$, and safety improved by about $20 \%$. Moreover, the results showed that the strategies of the vehicle base, both in terms of safety and traffic performance, did not differ significantly. By studying the application of counting data models as an alternative to analysis of the operating speed allowed on highways, Anastasopoulos and Mannering (2009) showed that counting data models with random parameters showed a more comprehensive understanding of factors that play an effective role in determining the maximum allowed operating speed on highways.

\section{METHODOLOGY}

The main subject of this study was the application of a new and more precise method for predicting accidents concerning the operating speed on the highway considered. Therefore, the proposed method should have the ability to be used in other geographic regions. It also should enhance the safety knowledge related to roads. After collecting the data, the average movement speed data was analyzed to achieve a reliable and close logical relationship 
between the severity of accidents and the speed. The mean distribution is equal to the estimated severity of the accident according to the speed, and the speed is correlated to the distribution average as a regression. SPSS software and the logit model were used in this research to estimate the severity of accidents in terms of speed.

\subsection{Study area}

In this study, the factors involving the severity of vehicle accidents on the Firuzkuh highway were investigated according to the operating speed. This highway is one of the most significant roads in northern Iran. It begins at Tehran, the capital of Iran, and connects to the city of Qaemshahr in Mazandaran province. The Firuzkuh highway has unique natural views, and it is one of the most famous highways in the north of the country. The shoulder width of this highway is $3 \mathrm{~m}$. It sometimes has heavy traffic, especially on holidays. This highway is one of the busiest highways in Iran. Due to the high traffic volume on this highway, which includes private cars, lorries, motorcycles, etc., it is necessary to conduct a study to determine the factors influencing the occurrence of accidents on this highway, one of the most important factors of which is speed. A view of the study area of Firuzkuh highway is illustrated in Fig. 1.

\subsection{Data collection}

In order to research the improvement of the road safety system, the accident data that covers topics such as times of accident, human specifications, environmental conditions, and ac-
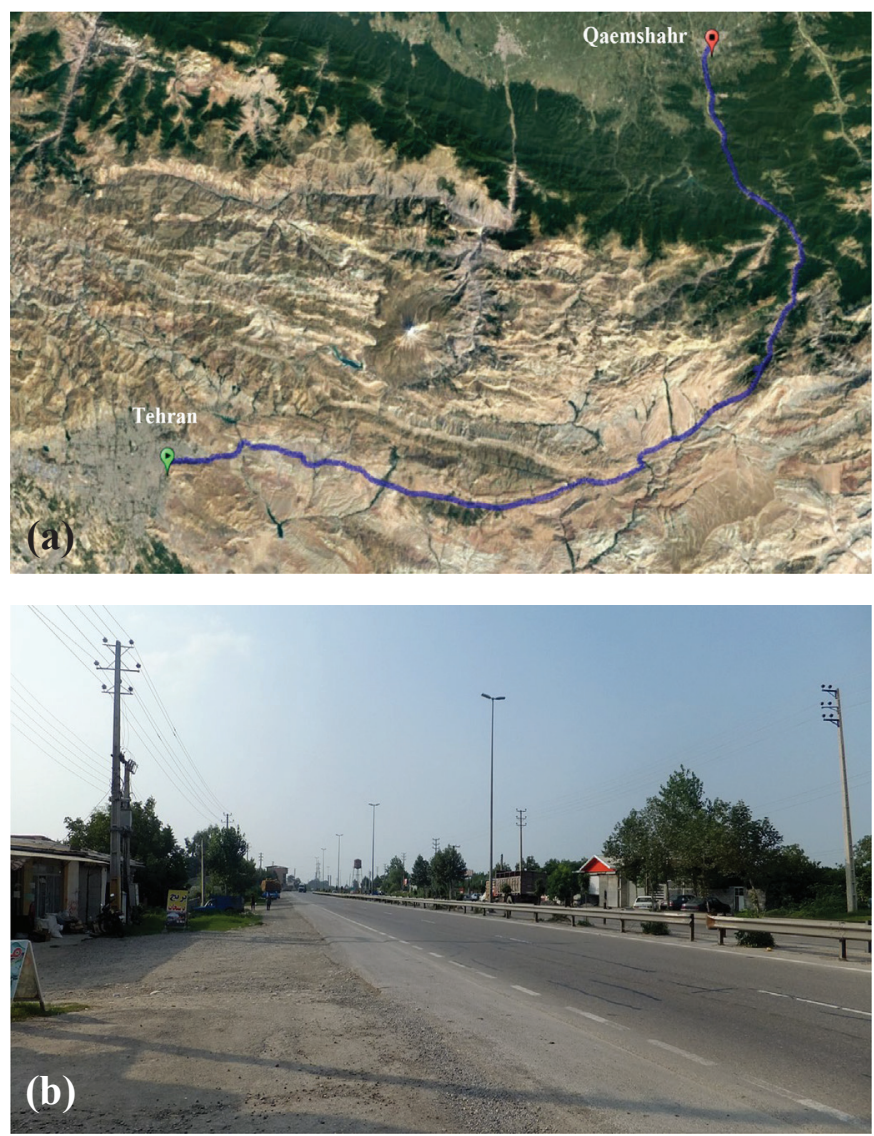

Fig. 1 The study area: a) Firuzkuh highway b) cross-section of the highway cident characteristics had to be collected. Unfortunately, traffic collisions are unpredictable, and there is no way to collect precise initial information and observe an accident when it occurs. Therefore, the police are the best way to obtain accident data. They are among the first to be present at the scene of an accident. Completing forms for traffic accidents is the beginning of the data collection process. These forms are known as "Kam No. 114" in Iran. The results of a series of referrals to the Traffic Police Center led to the collection of 12 months of accident data in 2017.

The data collected from the police included the number of injured and fatalities based on parameters such as age, gender, type of accident, type of road, etc., on the Firuzkuh highway. A total of 2536 accidents occurred in the statistical population. Also, data about the operating speed was extracted according to the Iran Road Maintenance \& Transportation Organization. Finally, the logit model for vehicle accidents was presented in terms of the role of the speed factor.

\subsection{Description of variables and modeling process}

For modeling the dataset, there is a need for two types of dependent and independent variables. The dependent variable of this research was different levels of the severity of an accident, which were classified into three categories: damage, injuries, and fatalities. Since the number of accidents leading to death was small compared to all the accidents, considering the three levels for the dependent variable did not provide good results as to the significance of the independent variables and fitting the model. Therefore, the fatal accidents were merged into the injury accidents, and the dependent variable was classified into two categories of damage and injury/fatal accidents. It should be noted that, in many cases, the reports of the officers on the scene of the accident are the injury accident type. However, the injured person may die after the transfer from the scene of the accident to a hospital. The number of discrepancies concerning death between the highway patrol and legal/medical statistics is generally due to this issue. Therefore, the integration of these two categories is sensible.

The independent variables included various types of parameters, such as the day and season of the accident, road surface conditions, type of road, lighting conditions, at-fault and not-at-fault vehicle type, age and gender of the drivers, weather conditions, operating speed, and types and causes of accidents. These parameters were collected from the Kam No. 114 form. Since there was no data on the operating speed variable in the accumulated data, the operating speed was taken from Iran Road Maintenance \& Transportation Organization, and the accumulated operating speed data were matched according to the hours and days of the accidents.

\subsection{Modeling method}

The logit model method includes models that describe the number of accidents, models related to the severity of the accident, and models representing the probability of the occurrence of an accident due to the speed factor.

\subsubsection{Logit analysis}

Whenever we want to establish a connection between the set of variables $x$ and a dependent variable such as $Y$, we face a multivariable problem. Various types of mathematical models 
have been used to consider the complexity of this relationship. The logit regression method is a mathematical method that is used to describe the relationship between multiple variables $x$ and a two-valued dependent variable. A function used in this method is an $S$-shaped function called a logit function, which can be applied in multi-valued problems (Vajari et al., 2020).

It is assumed that the variable $Y$ is a two-valued variable that covers the two selection levels. However, logit regression can also be applied to define the variable $Y$ in the multi-valued type. For example, the conditions are such so as to allow people to choose the mode of travel between personal vehicle modes, shared vehicles, and coaches, or consider the three categories of damage, injury, and fatal accidents in the classification of the severity of accidents. In this case, the general form of logit function is as follows (Hamed and Al-Eideh, 2020):

$$
P(Y=i x)=\frac{\exp \left[h_{i}(x)\right]}{1+\sum_{i=1}^{n} \exp \left[h_{i}(x)\right]}
$$

where:

$-h_{i}(x): \quad$ a function of independent variables $\mathrm{x}$,

$-P(Y=i x):$ the probability of the occurrence of the anticipated accident

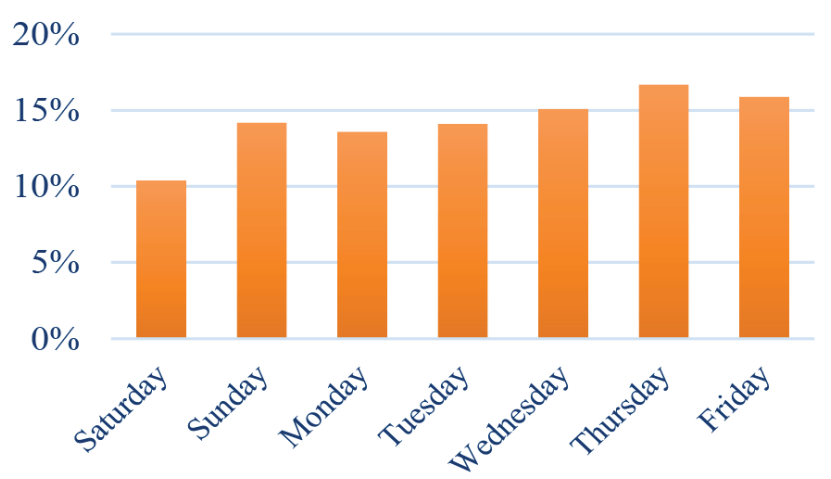

Fig. 2 Accident frequency based on the day

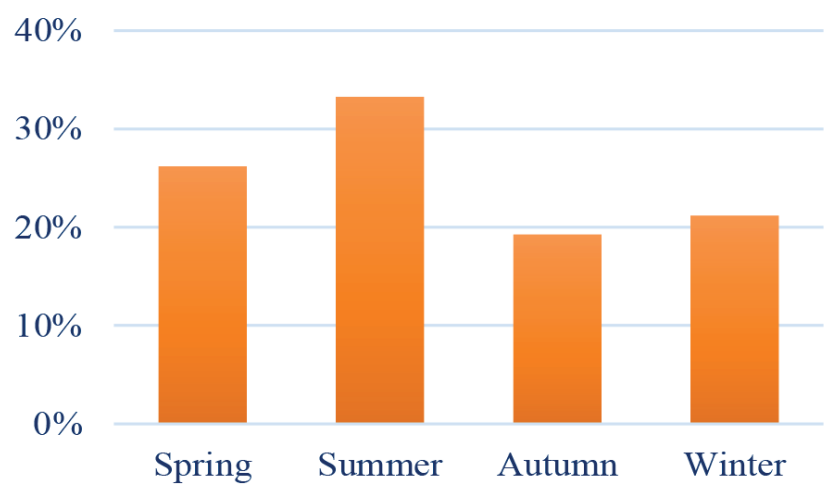

Fig. 4 Accident frequency based on the season

\section{RESULTS AND DISCUSSION}

In this step of the analysis, the frequency of the occurrence of the variables was investigated, see Tab. 1 . The accident data of the present study included 14 variables. However, since the goal of the present study was to investigate road accidents on the Firuzkuh highway, the study of ring roads and rural roads that are connected to this highway was avoided due to the lack of speed data. Therefore, all the variables studied include 13 independent variables and 1 dependent variable. Figs. 2 to 13 show accidents based on different parameters.

Tab. 1 The frequency of variables in frequency analysis

\begin{tabular}{lll}
\hline Variable type & Variable name & Frequency (\%) \\
\hline $\begin{array}{l}\text { Dependent variable } \\
\text { (accident severity) }\end{array}$ & Injury/fatal & 84.92 \\
& damage & 15.08 \\
\hline
\end{tabular}

As illustrated in the frequency analysis results, 22.3 percent of the drivers were driving faster than the maximum speed allowed. The significant point is that 87.7 percent of the drivers drove at speeds equal to or less than the maximum speed limit on this highway. Hence, in the modeling results, the effect of each speed variable on the modeling process should be considered. It can be determined whether each of the speed divisions affected the severity of the accidents.

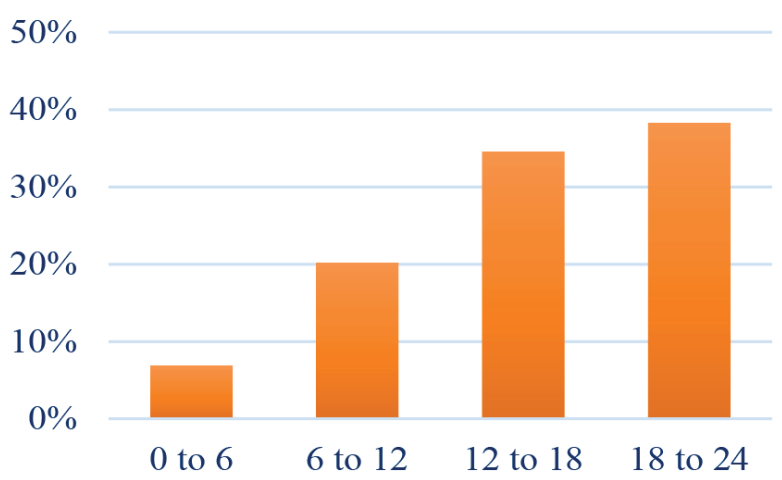

Fig. 3 Accident frequency based on the time of day

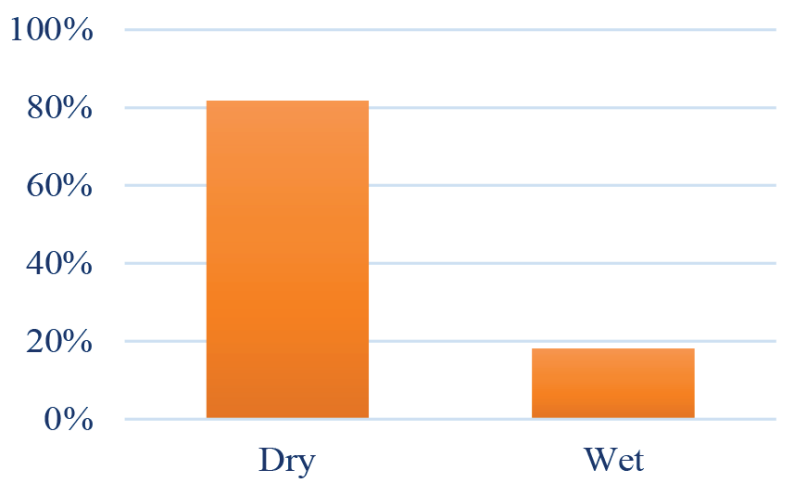

Fig. 5 Accident frequency based on the road surface conditions 


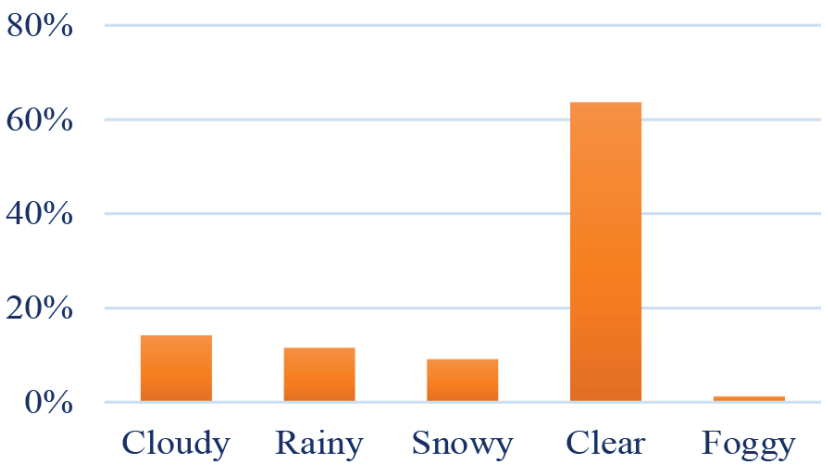

Fig. 6 Accident frequency based on the weather conditions

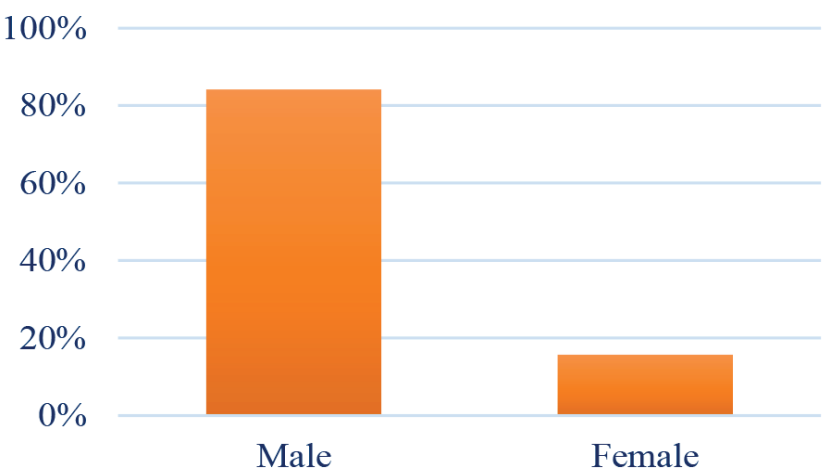

Fig. 8 Accident frequency based on the driver's gender

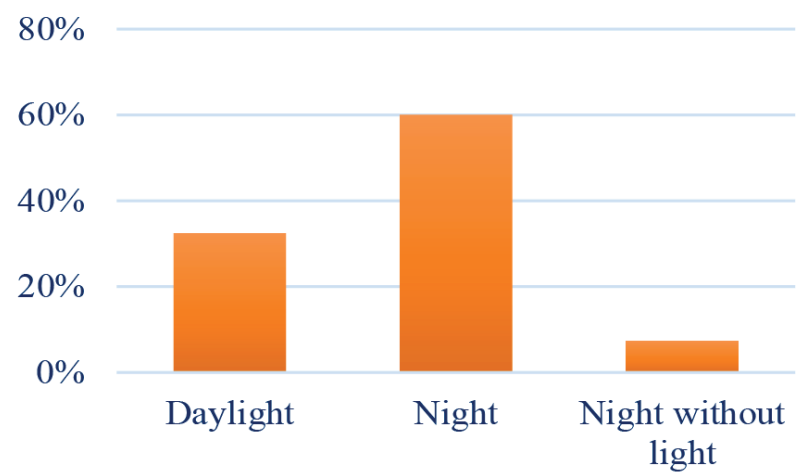

Fig. 7 Accident frequency based on the lighting conditions

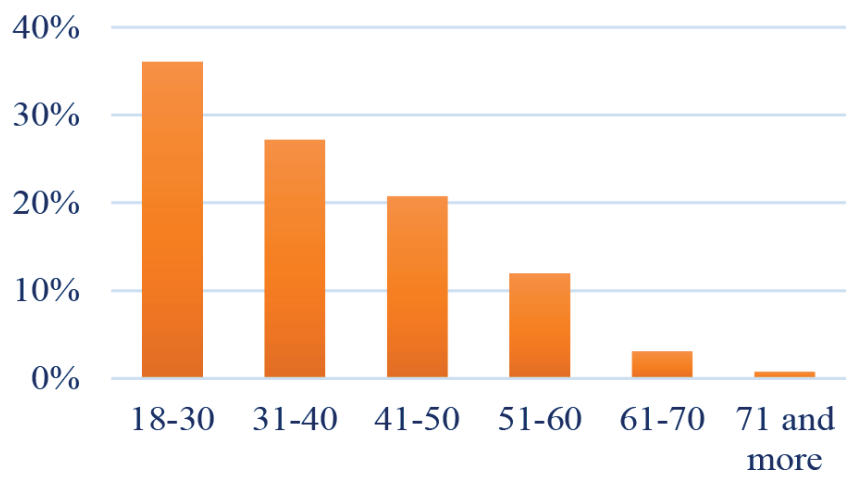

Fig. 9 Accident frequency based on the driver's age

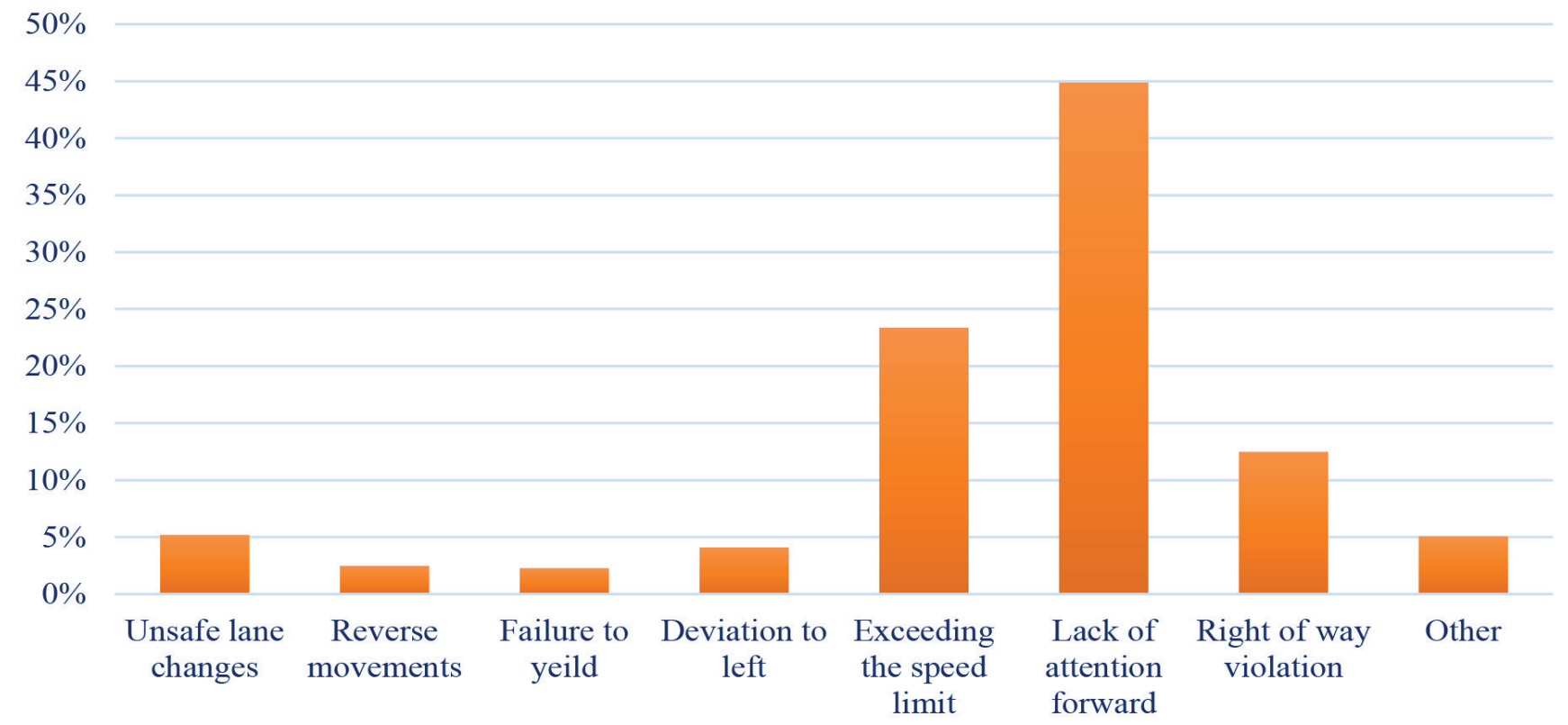

Fig. 10 Accident frequency based on the cause of an accident 


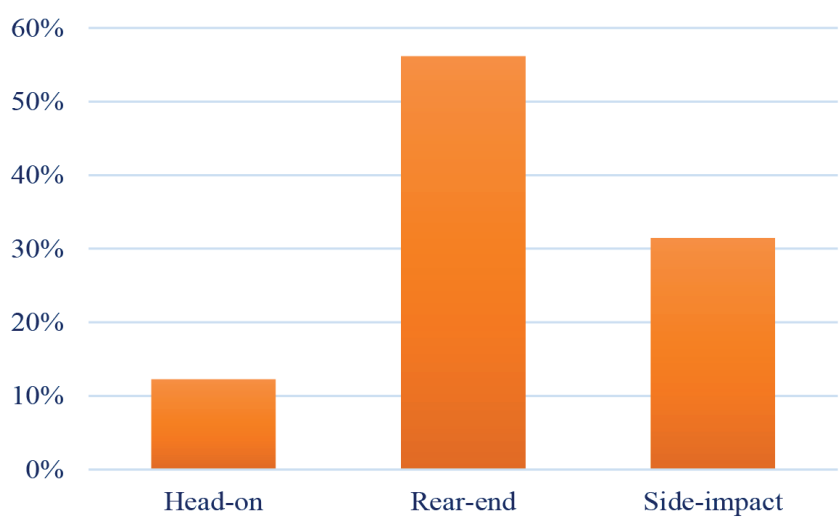

Fig. 11 Accident frequency based on the type of collision

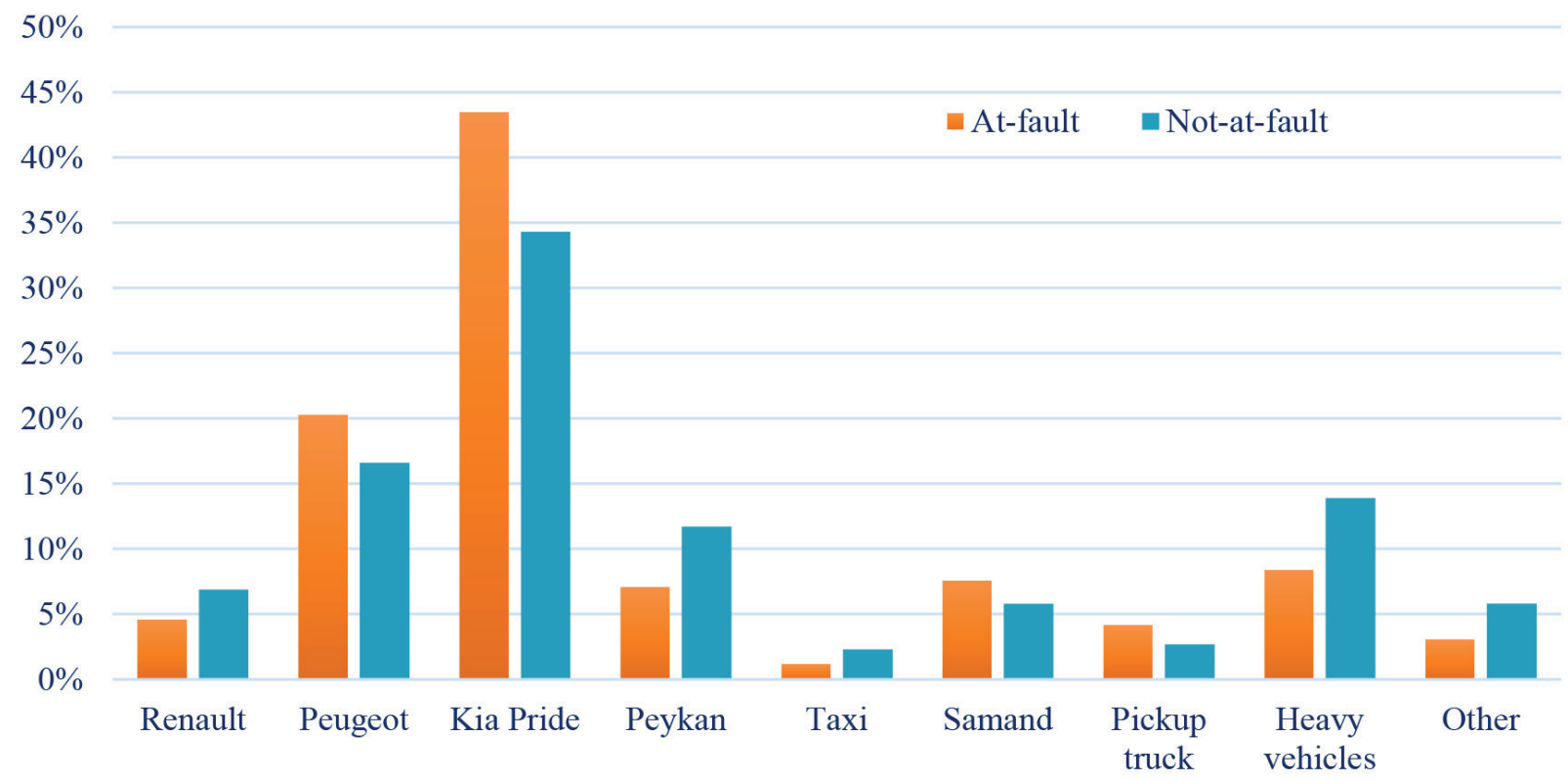

Fig. 12 Accident frequency based on the at-fault and not-at-fault type of vehicle

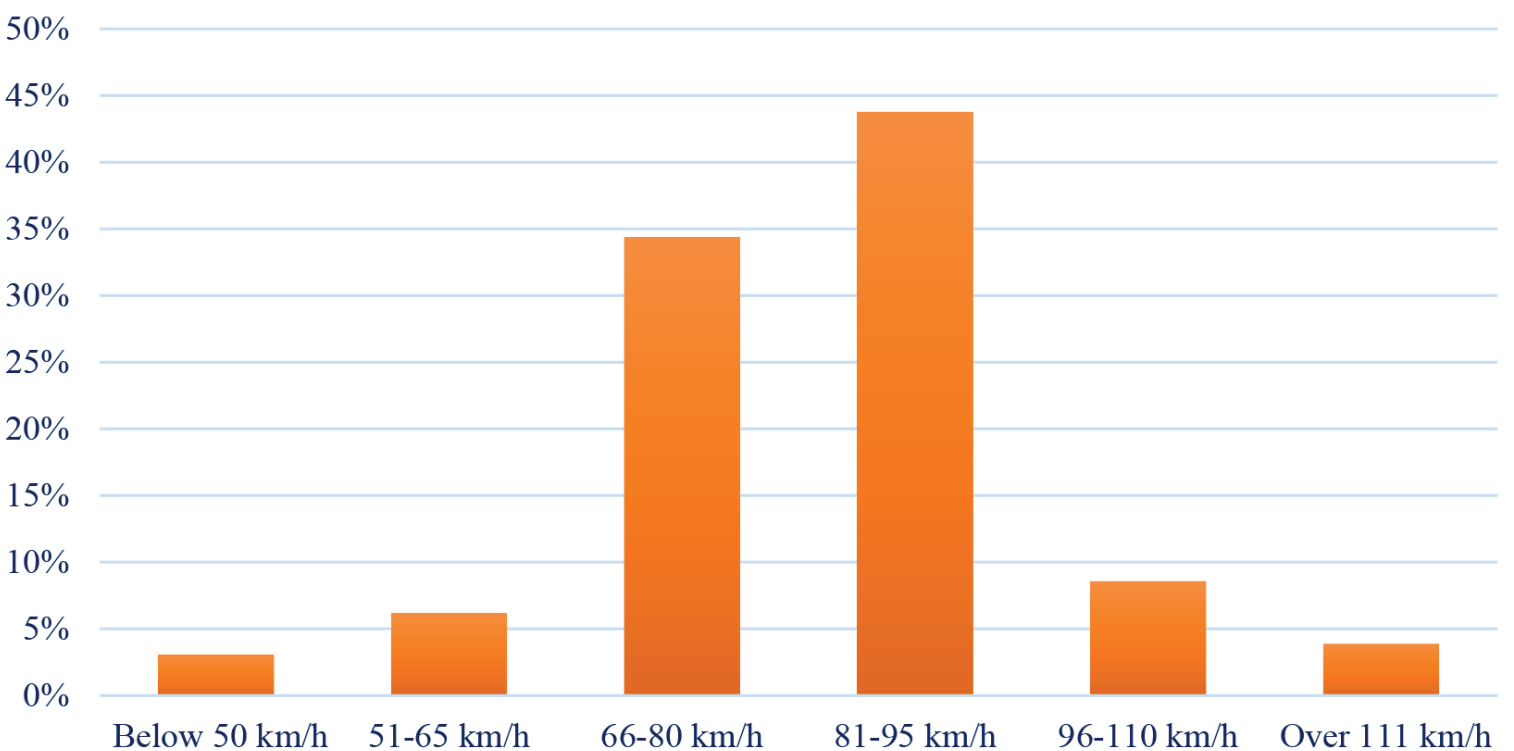

Fig. 13 Accident frequency based on the operating speed of drivers 
Tab. 2 Results of the Kolmogorov-Smirnov test

\begin{tabular}{|c|c|c|c|c|c|}
\hline \multirow{2}{*}{ Dimension } & \multicolumn{3}{|c|}{ Maximum difference } & \multirow{2}{*}{ Statistic } & \multirow{2}{*}{ Significance level* } \\
\hline & Absolute & Positive & Negative & & \\
\hline Accident hour & 0.189 & 0.067 & -0.189 & 0.189 & 0.0 \\
\hline Accident day & 0.033 & 0.233 & -0.229 & 0.033 & 0.0 \\
\hline Accident season & 0.206 & 0.306 & -0.197 & 0.206 & 0.0 \\
\hline Operating speed & 0.441 & 0.141 & -0.412 & 0.441 & 0.0 \\
\hline Road surface condition & 0.612 & 0.412 & -0.437 & 0.412 & 0.0 \\
\hline Daylight condition & 0.313 & 0.513 & -0.346 & 0.313 & 0.0 \\
\hline Cause of accident & 0.210 & 0.210 & -0.213 & 0.310 & 0.0 \\
\hline Driver gender & 0.429 & 0.429 & -0.466 & 0.429 & 0.0 \\
\hline Driver age & 0.196 & 0.196 & -0.164 & 0.196 & 0.0 \\
\hline Collision type & 0.018 & 0.329 & -0.317 & 0.218 & 0.0 \\
\hline Weather conditions & 0.264 & 0.188 & -0.264 & 0.364 & 0.0 \\
\hline At-fault vehicle type & 0.443 & 0.243 & -0.281 & 0.443 & 0.0 \\
\hline Not-at-fault vehicle type & 0.587 & 0.328 & -0.587 & 0.487 & 0.0 \\
\hline
\end{tabular}

*The error level is 0.01

\subsection{Evaluating the normality of the data}

For this purpose, we first needed to ensure the statistical distribution of the data, so the Kolmogorov-Smirnov test was used to check the normality of the distribution. Tab. 2 shows the results of this test for the dimensions. The results indicated that the test was significant; thus, these dimensions did not have a normal distribution. Therefore, nonparametric tests should be used for the deductions.

\subsection{Accident severity model}

For this goal, 13 independent variables and 1 dependent variable were defined in this study. They were converted into nominal variables ( 0 and 1$)$. The dependent variables, or the severity of the accidents, were three types of accidents, including damage, injury, and fatal accidents. According to the small number of fatal accidents (151 out of 2536), they accounted for the injury accidents. To enter variables in the logit equation, SPSS offers three methods, i.e., entering, backward, and forward. In the backward and forward methods, we dealt with the outputting or inputting of the variables, respectively. Selecting a method allowed us to choose how the independent variables could be entered for the analysis.

The final models of the above-mentioned three methods should be calculated to evaluate which one provides better outputs for the Firuzkuh accident model. Tab. 3 presents a summary of the models of these three methods (forward, backward, and entering), which include two criteria of the percentage of accuracy and goodness of fit of the model.

The results showed that the goodness of fit of the backward method was less than the other two methods; the backward method was therefore not suitable for modeling the accident. On the other hand, the two methods of forward and entering were the same as the goodness of fit. Therefore, the criteria of the percent- age of accuracy can determine the most suitable model. The forward method with a percentage of accuracy of 95.12 was the best method for the accident severity model of the Firuzkuh highway.

Tab. 3 Summary of the three forward, backward, and entering methods of the severity of the accident

\begin{tabular}{lcc}
\hline Logit regression & Accuracy & Goodness of fit \\
\hline Forward & 95.12 & 0.584 \\
Backward & 84.96 & 0.236 \\
Entering & 88.51 & 0.584 \\
\hline
\end{tabular}

Tab. 4 shows the coefficients of the forward model. The level of significance was zero at step 24 for the model, which was less than $5 \%$. Therefore, independent variables affected the dependent variable, thereby indicating appropriate fitting and comparability to the $\mathrm{F}$ statistic in normal regression analysis.

Tab. 4 Forward method results

\begin{tabular}{lccc}
\hline & Final step & df & Significance \\
\hline Step 1 & Step & 12 & 0.157 \\
\hline Step 24 & Model & 12 & 0.000 \\
\hline
\end{tabular}

By choosing the forward method and entering all 13 variables selected in the modeling process, the final model obtained from this method was calculated in 24 steps. Tab. 5 shows the variables entered in the final logit model. The Wald test examined the significance of the variables entered in the regression equation, which is comparable to the $t$ statistic in a normal regression.

The positive coefficients of some independent variables mean that the risk of the occurrence of an accident increased with a unit change in these kinds of variables. For those independent 
Tab. 5 Variables of the severity of the accident in the logit model on the Firuzkuh highway

\begin{tabular}{lcccc}
\hline Independent variables & Logarithm change $(\beta)$ & Standard deviation & Significance & Priority ratio \\
\hline Thursday & -1.528 & 0.953 & 0.002 & 0.217 \\
Hour 12-18 & 3.344 & 1.325 & 0.013 & 28.332 \\
Hour 18-24 & 2.937 & 1.285 & 0.024 & 18.859 \\
Summer season & -7.372 & 2.487 & 0.004 & 0.001 \\
Spring season & -1.917 & 0.724 & 0.009 & 0.147 \\
Sunny weather & -2.445 & 0.805 & 0.003 & 0.087 \\
Rainy weather & 2.752 & 1.156 & 0.015 & 15.674 \\
Lack of attention ahead & 1.118 & 0.643 & 0.083 & 3.059 \\
Exceeding speed limit & 2.203 & 0.772 & 0.005 & 9.052 \\
Male gender & -2.062 & 0.782 & 0.009 & 0.127 \\
Daylight & -4.346 & 1.421 & 0.003 & 0.013 \\
Speed $81-95(\mathrm{~km} / \mathrm{h})$ & 1.261 & 1.584 & 0.028 & 3.529 \\
Speed 96-110 $(\mathrm{km} / \mathrm{h})$ & 3.432 & 2.246 & 0.025 & 30.938 \\
Pride brand vehicle & 3.794 & 1.285 & 0.002 & 44.434 \\
Constant & 6.735 & 2.913 & 0.024 & 841.343 \\
\hline
\end{tabular}

variables with negative coefficients, the opposite is true. So the variables of the time of the accident (between 12:00 to 24:00), rainy weather conditions, the cause of the accident (lack of attention ahead), exceeding the speed limit, operating speeds of 96-110 $\mathrm{km} / \mathrm{h}$ and $81-95 \mathrm{~km} / \mathrm{h}$, and the type of vehicle at-fault (Pride, an Iranian vehicle brand) increased the risk of the occurrence of an accident on the Firuzkuh highway. On the contrary, with a unit change in the variables of the day of the accident (Thursday), the seasons (summer and spring), and sunny weather conditions, a male driver, and daylight conditions, the likelihood of accidents was decreased.

The most notable output of the Firuzkuh accident severity logit model is the high impact of Pride brand vehicles in increasing the likelihood of accidents. The variables of the day (Thursday) and seasons (summer and spring) of the accident indicated that more precautionary measures should be adopted and that the need for a police presence is felt. Also, according to the speed limit of $80-95 \mathrm{~km} / \mathrm{h}$ on most of the highway, the speed limit should be reduced in that the speed factor was one of the most effective variables regarding the occurrence of accidents on this highway.

\subsection{Role of the speed factor}

Since the main aim of this research was to investigate the role of the speed factor on the occurrence of accidents, a model should be developed without any other variables that affect the severity of accidents. The final model of the speed factor on the severity of accidents was obtained according to Tab. 6 .

As can be seen in Tab. 6, the speed variables below 50, 51 to 65,66 to 80 , and above $111 \mathrm{~km} / \mathrm{h}$ were among the variables with a significance level of more than $5 \%$. In other words, these speed ranges or the amount of the change of the logarithm had an impact on the accident severity variable, but the confidence coefficient was not at the confidence interval of $95 \%$. Also, by examining the priority ratio of the different speed ranges, it was determined that the speeds between $81-95$ and $96-110 \mathrm{~km} / \mathrm{h}$ had the highest priority ratio compared to the other variables. Moreover, since the coefficients of the variables were positive, with each unit of change in each speed value, the severity or risk of accidents was increased. In other words, as is obvious, with an increase in the speed range, accidents and the risk of the occurrence of accidents will increase.

Tab. 6 Variables used in the logit model to investigate the role of the speed factor on the severity of the accident

\begin{tabular}{lcccc}
\hline Independent variables: speed $(\mathrm{km} / \mathrm{h})$ & Logarithm change $(\beta)$ & Standard deviation & Significance & Priority ratio \\
\hline Below 50 & 1.846 & 0.856 & 0.112 & 6.334 \\
$51-65$ & 1.831 & 0.133 & 0.153 & 6.240 \\
$66-80$ & 1.002 & 0.112 & 0.062 & 2.724 \\
$81-95$ & 2.234 & 0.164 & 0.004 & 9.337 \\
$96-110$ & 2.103 & 0.095 & 0.037 & 8.191 \\
Over 111 & 1.916 & 0.087 & 0.125 & 6.794 \\
Constant & 1.047 & 0.171 & 0.028 & 2.849 \\
\hline
\end{tabular}




\section{CONCLUSION}

After analyzing the accident data by statistical analysis and the modeling of the accident data using the logit model, the causes of the risk of the occurrence of accidents on the Firuzkuh highway were concluded. Also, for a more practical use of this study, some suggestions have been presented according to the results. The most important results of this study are as follows:

- The highest number of accidents occurred during the hours of 18 to 24 on Thursdays in the summer under the following conditions: a dry road surface, sunny weather, the lack of attention ahead, and exceeding the maximum speed limit as the cause of an accident, a rear-end accident as the type of collision, ages between 18 to 30 and male drivers, a Pride brand vehicle, and speeds between 81 to $95 \mathrm{~km} / \mathrm{h}$.

- The largest share of the vehicles and likelihood of accidents on the Firuzkuh highway vehicle accidents belonged to the Pride brand vehicle, which indicates the necessity of the manufacturer paying more attention to enhance the Pride brand vehicle's safety.

- The Kolmogorov-Smirnov test results indicated that the test was significant; as a result, the dimensions did not have a normal distribution. Therefore, nonparametric tests should be used.

- According to the modeling results obtained from the backward, forward, and entering methods, the forward method model with a 95.12 level of accuracy at step 24 was the best method for building the accident severity logit model of the Firuzkuh highway.

- According to the outputs of the logit model, with a unit change in the independent variables such as the time of the accident from 12:00 to 24:00, rainy weather conditions, cause of accidents (the lack of attention ahead), and exceeding the speed limit, the operating speed of 96-110 and $86-95 \mathrm{~km} / \mathrm{h}$, the type of vehicle at-fault (the Pride brand), the likelihood of accidents increased. However, with a unit change in the variables with negative coefficients (Thursday, summer and spring seasons, sunny weather conditions, male drivers, and daylight), the risk of accidents on the Firuzkuh highway declined.
- According to the results, the logit model indicated the urgency of a preventive procedure and a greater presence of the police on the accident day of Thursday and in the summer and spring seasons. Also, with a speed limit of 80-95 $\mathrm{km} / \mathrm{h}$ on most of the Firuzkuh highway, this speed limit was one of the most influential variables in increasing the likelihood of accidents. This demonstrates the importance of reducing the maximum speed limit of this highway.

- In order to make the present study more practical, some strategies are suggested based on the results, e.g., the need to create strict regulations in dealing with vehicle manufacturers whose vehicles have the highest share and likelihood of accidents and imposing fines on them; increasing the police presence between the hours of 12:00 to 24:00 on Thursdays, Fridays, and during the summer, and adopting preventive procedures; increasing the police presence in the areas with the highest percentage of exceeding the speed limit or installing automated speed enforcement mechanisms in these areas; and reducing the speed limit for those sections of the highway that have a speed limit greater than $85(\mathrm{~km} / \mathrm{h})$.

- For future research work, other machine learning techniques (Taleghani and Taleghani, 2013; Nadimia et al., 2017; Hu et al., 2020; Shan et al., 2020; Zhang et al., 2020b; Tu et al., 2021; Yu et al., 2021), deep learning models (Xu et al., 2018; Li et al., 2019; Qiu et al., 2019; Chen et al., 2020; Lv and Qiao, 2020; Addeh and Iri, 2021), and optimization algorithms (Golilarz et al., 2020; Golrokh et al., 2020; Zhang et al., 2020a) can be incorporated into the proposed approaches to obtain more accurate results. Moreover, the traffic volume is effective in relating to the speed of vehicles, which in turn can be effective in reducing the severity of accidents; therefore, the traffic volume and its interactive effect with speed should also be considered and can be examined in another study.

\section{Declarations}

The authors declare that they have no conflict of interest. In this study, Iranian governmental organizations have not been partners and sponsors, and this study is purely academic.

\section{Funding}

This research did not receive any specific grant from funding agencies in the public, commercial, or not-for-profit sectors.

\section{REFERENCES}

Abbasi, E. - Li, Y., 2021. A Comprehensive Review of Driver's Attention and the Evaluation Methods. Computational Research Progress in Applied Science \& Engineering (CRPASE) 7.

Addeh, A. - Iri, M., 2021. Brain tumor type classification using deep features of MRI images and optimized RBFNN. Engineering Transactions 2 .

Anastasopoulos, P.C. - Mannering, F.L., 2009. A note on modeling vehicle accident frequencies with random-parameters count models. Accident Analysis \& Prevention 41, 153-159.
Ataeian, S. - Mostafavi, A. - Nabiloo, R., 2020. Performance Analysis of Fixed Route Shared Taxi Services (Jitney)-Case Study of Tehran, Iran. Computational Research Progress in Applied Science \& Engineering (CRPASE) 6.

Ayati, 2012. Traffic Accidents Cost of Iran. Ferdowsi University, Publisher.

Ayati, A. - Abbasi, A., 2011a. Application of Zero-Inflated Regression Models in Modeling Accidents on Urban Highways. mdrsjrns 11, 1-15. 
Ayati, E. - Abbasi, E., 2011b. Investigation on the role of traffic volume in accidents on urban highways. Journal of safety research 42, 209-214.

Babaie, S. - Seyedhosseini, M. - Motadel, M., 2021. The Parameters Affecting the Mathematical Programming Model of the Appropriate Transportation System. Journal of System Management 7, 1-22.

Chang, L.-Y. - Mannering, F., 1999. Analysis of injury severity and vehicle occupancy in truck-and non-truck-involved accidents. Accident Analysis \& Prevention 31, 579-592.

Chen, H. - Chen, A. - Xu, L. - Xie, H. - Qiao, H. - Lin, Q. - Cai, K., 2020. A deep learning $\mathrm{CNN}$ architecture applied in smart near-infrared analysis of water pollution for agricultural irrigation resources. Agricultural Water Management 240, 106303.

Dadashpoor, H. - Azizi, P. - Moghadasi, M., 2019. Analyzing spatial patterns, driving forces and predicting future growth scenarios for supporting sustainable urban growth: Evidence from Tabriz metropolitan area, Iran. Sustainable Cities and Society 47, 101502 .

Delen, D. - Sharda, R. - Bessonov, M., 2006. Identifying significant predictors of injury severity in traffic accidents using a series of artificial neural networks. Accident Analysis \& Prevention 38, 434-444.

Eisenstadt, S.N. - Schramm, W. - Rogers, E.M. - Oshima, H.T. Lerner, D., 2021. 3. The Changing Vision of Modernization and Development, Communication and Change, University of Hawaii Press, pp. 31-64.

Golilarz, N.A. - Gao, H. - Addeh, A. - Pirasteh, S., 2020. ORCA Optimization Algorithm: A New Meta-Heuristic Tool for Complex Optimization Problems, 2020 17th International Computer Conference on Wavelet Active Media Technology and Information Processing (ICCWAMTIP), pp. 198-204.

Golrokh, F.J. - Azeem, Hasan, 2020. Eco-efficiency Evaluation in Cement Industries: DEA Malmquist Productivity Index Using Optimization Models. ENG Transactions 1.

Hamed, M.M. - Al-Eideh, B.M., 2020. An exploratory analysis of traffic accidents and vehicle ownership decisions using a random parameters logit model with heterogeneity in means. Analytic methods in accident research 25, 100116.

Holdridge, J.M. - Shankar, V.N. - Ulfarsson, G.F., 2005. The crash severity impacts of fixed roadside objects. Journal of Safety Research 36, 139-147.

Hu, J. - Chen, H. - Heidari, A.A. - Wang, M. - Zhang, X. - Chen, Y. - Pan, Z., 2020. Orthogonal learning covariance matrix for defects of grey wolf optimizer: Insights, balance, diversity, and feature selection. Knowledge-Based Systems, 106684.

Khorashadi, A. - Niemeier, D. - Shankar, V. - Mannering, F., 2005. Differences in rural and urban driver-injury severities in accidents involving large-trucks: an exploratory analysis. Accident Analysis \& Prevention 37, 910-921.

Li, T. - Xu, M. - Zhu, C. - Yang, R. - Wang, Z. - Guan, Z., 2019. A deep learning approach for multi-frame in-loop filter of HEVC. IEEE Transactions on Image Processing 28, 5663-5678.
Lv, Z. - Qiao, L., 2020. Deep belief network and linear perceptron based cognitive computing for collaborative robots. Applied Soft Computing 92, 106300.

Milton, J.C. - Shankar, V.N. - Mannering, F.L., 2008. Highway accident severities and the mixed logit model: an exploratory empirical analysis. Accident Analysis \& Prevention 40, 260-266.

Nadimia, N. - Alavia, S.S.N. - Mirhosseinia, A.H.Z. - Amirib, A.M., 2017. Proposing a Model for Ranking Hotspots in Rural Roads Using a Multi-criteria Decision-making Method. Computational Research Progress in Applied Science \& Engineering (CRPASE) 3.

Qiu, T. - Shi, X. - Wang, J. - Li, Y. - Qu, S. - Cheng, Q.,-Cui, T. - Sui, S., 2019. Deep learning: A rapid and efficient route to automatic metasurface design. Advanced Science 6, 1900128.

Savolainen, P. - Mannering, F., 2007. Probabilistic models of motorcyclists' injury severities in single-and multi-vehicle crashes. Accident Analysis \& Prevention 39, 955-963.

Shahi, Nejad, A. - Sheikholeslami, 2005. Modeling of Motorcycles Accidents Intensity in the City of Tehran. Journal of Transportation Research 3.

Shan, W. - Qiao, Z. - Heidari, A.A. - Chen, H. - Turabieh, H. Teng, Y., 2020. Double adaptive weights for stabilization of moth flame optimizer: Balance analysis, engineering cases, and medical diagnosis. Knowledge-Based Systems, 106728.

Taleghani, M. - Taleghani, A., 2013. Identification and Ranking of Factors affecting the implementation of Knowledge Management based on TOPSIS Technique. ENG Transactions 1.

Torabi, Moghadam, R., 2010. Modelling the risk of accidents in urban highways. Journal of Transportation 18.

Tu, J. - Chen, H. - Liu, J. - Heidari, A.A. - Zhang, X. - Wang, M. - Ruby, R. - Pham, Q.-V., 2021. Evolutionary biogeography-based whale optimization methods with communication structure: Towards measuring the balance. Knowledge-Based Systems 212, 106642.

Vajari, M.A. - Aghabayk, K. - Sadeghian, M. - Shiwakoti, N., 2020. A multinomial logit model of motorcycle crash severity at Australian intersections. Journal of safety research 73, 17-24.

Xu, M., Li, T. - Wang, Z. - Deng, X. - Yang, R. - Guan, Z., 2018. Reducing complexity of HEVC: A deep learning approach. IEEE Transactions on Image Processing 27, 5044-5059.

Yang, X.-t. - Fang, Y.-p. - Qiu, X.-p. - Zhu, F.-b., 2018. Gradient effect of road transportation on economic development in different geomorphic regions. Journal of Mountain Science 15.

Yu, C. - Chen, M. - Cheng, K. - Zhao, X. - Ma, C. - Kuang, F. - Chen, H., 2021. SGOA: annealing-behaved grasshopper optimizer for global tasks. Engineering with Computers, 1-28.

Zhang, X. - Wang, J. - Wang, T. - Jiang, R. - Xu, J. - Zhao, L., 2020a. Robust Feature Learning for Adversarial Defense via Hierarchical Feature Alignment. Information Sciences.

Zhang, Y. - Liu, R. - Wang, X. - Chen, H. - Li, C., 2020b. Boosted binary Harris hawks optimizer and feature selection. Engineering with Computers, 1-30. 